\title{
Implementing Quality Management Standards in Conducting Courses at Higher Education Institutes (HEI)
}

\author{
ljlal Haider, Muhammad Yahya \\ Army Public College of Management \& Sciences, Rawalpindi, Pakistan \\ ljlal@apcoms.edu.pk, engineeryahya@yahoo.com
}

\begin{abstract}
:
The only doubt in saying that education is a key to sustainability of any nation is Quality. Education has experienced a major paradigm shift in recent years. It has become a service industry affecting its various stakeholders from faculty and students to society. Its vast impact has intrigued the application of management principals such as project management and quality management to assure best results in terms of its various deliverables. Higher education, in particular, for its direct and immediate applicability in society needs a concrete quality assurance system. According to foreign researchers and practitioners, future is the age of knowledge, knowledge organizations, new economy that forces organizations to create new methods of work, competences, processes, management methods and the principles of strategic management. Knowledge is obtained through thinking, experience, observation, information channels and other sources. Quality management standard ISO 9000 has already been investigated and implemented in educational institutes which has resulted in development of IWA2 (International Workshop Agreement). However most of such work is focused on assuring quality in organizational structure of higher education institutes. In this research we will investigate various aspects of implementing quality management standards in various activities of conducting a course at a higher education institute. These activities should be based on the 4 $P$ 's of management i.e. Performance through Planning and managing People and Processes, where people concerned are instructors and students and processes range from instruction to assessment. Quality in conducting courses can be ensured by leadership and customer satisfaction from the stakeholders and planning processes, documenting and implementing them followed by auditing. Our work will follow the three stages of (a) preparation work for the creation of quality management system, (b) the preparation and implementation of the documents of the quality management system and (c) the preparation of the quality management system for certification as suggested by earlier research.
\end{abstract}

